\title{
ROS1-positive Inflammatory Myofibroblastic Tumor of the Small Bowel Causing Obstruction: A Case Report
}

\author{
Anatoly Budylev $^{1 *}$, Irit Solar ${ }^{2}$, Rivka Kessner $^{1,3}$, Asaf Aizic ${ }^{2}$ \\ 1. Department of Radiology, Tel Aviv Sourasky Medical Center, Tel Aviv, Israel \\ 2. The Institute of Pathology, Tel Aviv Sourasky Medical Center, Tel Aviv, Israel \\ 3. Department of Diagnostic Imaging, Sackler Faculty of Medicine, Tel Aviv University, Tel Aviv, Israel
* Correspondence: Anatoly Budylev, Department of Radiology, Tel-Aviv Sourasky Medical Center, 6 Weizmann Street, Tel-Aviv 6423906, Israel
(入 anatoly.bud.1987@gmail.com)

\begin{abstract}
Inflammatory Myofibroblastic Tumors (IMTs) are rare fibroblastic/myofibroblastic neoplasms that affect predominately pediatric patients and young adults. Almost half of the patients with IMTs have a chromosomal abnormality in the Anaplastic Lymphoma Kinase 1 gene on chromosome $2 \mathrm{p} 23$. Although these tumors occur primarily in the lung, lesions have been reported in a variety of intra-abdominal organs like the liver, spleen, and mesentery. Small bowel IMTs are particularly rare. IMTs generally pursue a benign clinical course, however intra-abdominal and retroperitoneal tumors have typically shown higher local recurrence and even distant metastases. The most common presenting symptoms of an intra-abdominal IMT are abdominal pain and change in bowel habits. Laboratory results are nonspecific and can include anemia and minor elevation of inflammatory markers like C-reactive protein. We report an unusual case of IMT in the small bowel causing the obstruction.
\end{abstract}

\section{CASE REPORT}

\section{CASE REPORT}

A generally healthy 23 years old woman with a family history of colon cancer presented to our emergency room (ER) with complaints of right lower quadrant abdominal pain and diarrhea.

She underwent a physical examination and abdominal ultrasound (US) that did not reveal any evidence of acute appendicitis. The blood tests have shown increased CRP of 53 $\mathrm{mg} \backslash \mathrm{L}$ (normal 0.03-5 mg\) without leukocytosis. She was discharged with a diagnosis of gastroenteritis and was given antibiotic treatment. After 5 days, the abdominal pain became constant and worse, so she returned to the ER. Physical examination revealed a generally distended abdomen, no apparent palpable masses, and no signs of peritonitis. The blood tests showed an increased CRP of $42.8 \mathrm{mgl}$, again without leukocytosis or any other abnormality. A transvaginal US was performed and revealed a well-defined solid mass measuring 44 * $39 \mathrm{~mm}$ to the left of the uterus. The solid mass was 
heterogeneous with the avid flow on Doppler images (Figure 1). An abdominal computed tomography (CT) scan with parenteral and intravenous contrast materials was performed and confirmed the presence of a mass in the ileum causing small bowel obstruction (Figure 2). There were no other acute findings in the abdominal or pelvic organs.

Based on the CT findings, the patient underwent urgent small bowel resection. On laparotomy, a large tumor with prominent vascularity was found to arise from the distal ileum. There was no evidence of metastasis. The mass was resected, along with involved sections of the small bowel, and a primary small bowel anastomosis was performed. There were no postoperative complications.

\section{DISCUSSION}

\section{Etiology \& Demographics:}

The first description of IMT was in 1937 as a lung tumor predominantly appearing in pediatric patients and young adults [1].

The World Health Organization (WHO) classified the IMT as a fibroblastic/myofibroblastic neoplasm of intermediate biologic potential because of its potential for invasion of surrounding structures and development of local recurrence and distant metastases $[2,3]$. There are several different names for IMT, including: inflammatory pseudotumor, plasma cell granuloma, fibrous histiocytoma, solitary mast cell tumor, and fibroxanthoma [4].

The factors responsible for the development of IMT are still not clearly established. IMT may represent an immunologic response to an infectious or noninfectious agent, or it may be a true tumor. Campylobacter jejuni, Epstein-Barr virus, and Escherichia coli have been associated with IMT. Also, trauma, steroid use, abdominal surgery, and genetic factors have been reported, but the pathogenesis of IMT remains unclear $[5,6]$.

On pathological examination: The tumor in this case was non-encapsulated and infiltrative (Figure 3), showing alternating hypocellular areas with myxoid background and hypercellular fascicular areas with a collagenous background. The tumor cells were uniformly spindled, showing scant to moderate pale eosinophilic cytoplasm with a round to elongated bland nuclei and conspicuous nucleoli. Prominent lymphoplasmacytic infiltrate with minor polymorphonuclear cells component was also identified. The mitotic rate was low (4/10 HPF), and no tumor necrosis was identified (Figure 4).

On immunohistochemistry, the tumor cells were negative for ALK, Keratins, c-kit, DOG1, STAT6, beta-catenin, S100, and Desmin, and showed immunoreactivity solely for SmoothMuscle Actin, Vimentin, and ROS1 (Figure 5).

Molecular pathology studies were performed by a targeted next-generation sequencing (NGS) based assay to detect gene fusions from formalin-fixed paraffin-embedded (FFPE) tissues. A FN1-ROS1 fusion (chr2:216256355,chr6:117650609) was identified using the FusionPlex Sarcoma NGS Panel (Archer Dx, Boulder, CO.), based on a modified amplicon approach, referred to as Anchored Multiplex PCR. FN1-ROS1 fusions were recently reported in a few cases of ALK-negative IMTs.

\section{Clinical \& Imaging findings:}

Presenting symptoms depend on the primary involved site. As mentioned before, the lung is the most commonly affected site. However, extra-pulmonary IMTs may include the mesentery-omentum, upper respiratory tract, genitourinary tract, retroperitoneum, neck, spleen, brain, pancreas, liver, and the intestines $[1,6]$

Patients with intra-abdominal IMTs most commonly present with intermittent abdominal pain due to the solid mass and abdominal distention, weight loss, malaise, anorexia, and vomiting $[4,7,8]$. Rarely, the presentation may be complicated by an intussusception, acute abdomen mimicking acute appendicitis, or intestinal obstruction, as was the case in our patient.

Laboratory abnormalities are present in a minority of the patients and include anemia, increased CRP, as in our patient, and sometimes thrombocytosis [6,7]. Leukocytosis is rare [5].

The radiological findings of IMTs are non-specific. The Xray may be helpful only for IMTs with bone involvement. It can show bone destruction, clear and sharp boundaries, no calcification or ossification, expansive growth, internal groundglass opacities, an unbroken sclerotic rim without cortical involvement [18].

On US, IMTs can appear as hypoechoic or hyperechoic masses with ill-defined or well-circumscribed edges and a variable Doppler appearance, with increased vascularity [15]. The US is usually the first imaging technique when IMTs appear in specific locations, such as testicles or neck. In other locations, its role is limited.

CT and MRI are the most used imaging tools in the evaluation of IMTs. On contrast-enhanced CT, IMTs can appear as homogeneous or heterogeneous lesions, with variable enhancement on delayed acquisitions due to presence of fibrous component. On T1-weighted and T2-weighted sequences, IMTs usually show low signal intensity, reflecting the presence of fibrotic tissue [15].

PET-CT can show varied FDG from low to high, which may be due to tumor cellularity, biological behaviors of the tumor cells, the composition and the proportion of inflammatory cells, and the extent of activation of the inflammatory cells [16]. The scintigraphic examination may be normal [17].

\section{Treatment \& Prognosis:}

The treatment of choice is complete surgical excision, and long-term follow-up with physical examination, imaging like CT, and blood tests [9]. Chemotherapy with or without radiotherapy has been used for patients with incomplete tumor resection, positive margins, tumors not amenable to resection, and metastatic disease. There is no definitive data establishing the efficacy of adjuvant therapy [10] for patients following complete resection. The primary treatment for IMT can be 
corticosteroids - which produce tumor regression and reduction of the inflammatory reaction in the surrounding tissues [11].

Like non-small cell lung cancer, the identification of ALK or ROS1 rearrangements provides a potential therapeutic option for some patients with aggressive IMTs using Tyrosine kinase inhibitors targeting ALK oncoprotein, such as crizotinib.

\section{Differential Diagnosis:}

Because IMTs are arising in different body locations with non-specific imaging pictures, in most cases, it is impossible to distinguish IMT from other tumors - the diagnosis is generally made on pathological examination.

The microscopic morphology of spindle cell proliferation with lymphoplasmacytic infiltration raises the suspicion for IMT. However, other gastrointestinal stromal tumors may show comparable histological findings and should be excluded using other immunohistochemistry assays.

Unlike IMTs, Gastrointestinal stromal tumors (GISTs) are usually immunoreactive for c-kit and, DOG1 and smoothmuscle tumors should be diffusely positive for Desmin and Caldesmon. Peripheral nerve sheath tumors, melanomas, and clear-cell sarcomas can be excluded by negative immunoreaction for S100. The negativity of the tumor cells for STAT6 and beta-catenin excludes solitary fibrous tumors and fibromatosis, respectively.

Positive immunohistochemistry for ALK shows a good concordance with the presence of ALK gene rearrangement, and it is a crucial marker for the accurate diagnosis of IMT. However, approximately $50 \%$ of IMT cases, including ours, are ALK-negative and harbor other gene rearrangements, mainly of ROS1, ETV6, and/or NTRK3.

ROS1 expression by immunohistochemistry is useful for the diagnosis of ALK-negative IMTs, as it correlates with ROS1 gene rearrangements $[13,14]$.

\section{TEACHING POINT}

Inflammatory Myofibroblastic Tumor is a solid tumor that can rarely present in a young adult as acute abdominal pain with bowel obstruction. A precise diagnosis should be based on histological findings, and complete surgical resection is necessary. Clinical and laboratory follow-up is mandatory due to the increased risk of local recurrence.

\section{REFERENCES}

1. Koyuncuer A. Inflammatory myofibroblastic tumor of the small-bowel mesentery: a case report of nonspecific clinical presentation and a review of the literature. Int J Surg Case Rep. 2014;5(12):1214-7. PMID: 25437679.

2. Coffin CM, Watterson J, Priest JR, Dehner LP. Extrapulmonary inflammatory myofibroblastic tumor (inflammatory pseudotumor). A clinicopathologic and immunohistochemical study of 84 cases. Am J Surg Pathol. 1995;19(8): 859-72. PMID: 7611533.

3. Fletcher, CDM, Unni KK, Mertens F. (eds). Pathology and Genetics of Tumors of Soft Tissue and Bone. World Health Organization Classification of Tumours. 2002, Lyon: IARC Press. 91-93. ISBN-13 978-92-832-2413-6.

4. Dhouib A, Barrazzone C, Reverdin A, Anooshiravani M, Hanquinet S. Inflammatory myofibroblastic tumor of the lung: a rare cause of atelectasis in children. Pediatr Radiol. 2013;43:381-4. doi:10.1007/s00247-012-2508-x.

5. Dalton BG, Thomas PG, Sharp NE, Manalang MA, Fisher JE, Moir CR, et al. Inflammatory myofibroblastic tumors in children. J Pediatr Surg. 2016 Apr;51(4):541-4. doi: 10.1016/j.jpedsurg.2015.11.015.

6. Appak YÇ, Sahin GE, Ayhan S, Taneli C, Kas?rga E. Inflammatory myofibroblastic tumor of the colon with an unusual presentation of intestinal intussusception. Eur J Pediatr Surg Rep. 2014;2:54-7. doi:10.1055/s-0034-1370774.

7. DiFiore JW, Goldblum JR. Inflammatory myofibroblastic tumor of the small intestine. J Am Coll Surg. 2002;194(4):5026. PMID: 11949755

8. Bonnet JP, Basset T, Dijoux D. Abdominal inflammatory myofibroblastic tumors in children: report of an appendiceal case and review of the literature. J Pediatr Surg. 1996;31(9):1311-4. PMID: 23056847.

9. Spencer $H$. The pulmonary plasma cell/histiocytoma complex. Histopathology 1984;8:903-16. PMID: 6098549.

10. Kovach SJ, Fischer AC, Katzman PJ, Salloum RM, Ettinghausen SE, Madeb R, et al. Inflammatory myofibroblastic tumors. J Surg Oncol. 2006. 94(5): p. 385-91. PMID: 16967468

11. Li JY, Yong TY, Coleman M, Astill D, Passaris G, Juneja $\mathrm{R}$, et al. Bilateral renal inflammatory pseudotumour effectively treated with corticosteroid. Clin Exp Nephrol. 2010;14(2):1908. PMID: 19921350.

12. Gleason BC, Hornick JL. Inflammatory myofibroblastic tumours: where are we now? J Clin Pathol. 2008;61(April (4)):428-37. doi:10.1136/jcp.2007.049387.

13. Yamamoto H, Yoshida A, Taguchi K, Kohashi K, Hatanaka Y, Yamashita A, et al. "ALK, ROS 1 and NTRK 3 gene rearrangements in inflammatory myofibroblastic tumours." Histopathology 2016;69(1):72-83.

14. Hornick JL, Sholl LM, Dal Cin P, Childress MA, Lovly CM. Expression of ROS1 predicts ROS1 gene rearrangement in inflammatory myofibroblastic tumors. Modern Pathology 2015;28(5):732-739.

15. Jon Etxano Cantera, María Páramo Alfaro, David Cano Rafart, Romina Zalazar, Maite Millor Muruzabal, Paula García Barquín, and Isabel Vivas Pérez. Inflammatory myofibroblastic 
tumours: a pictorial review. Insights Imaging. 2015 Feb. 6(1): 85-96. PMID: 25519466

16. Aisheng Dong, Yang Wang, Hui Dong, Jing Gong, Chao Cheng, Changjing Zuo, Jianping Lu. Inflammatory myofibroblastic tumor: FDG PET/CT findings with pathologic correlation Clin Nucl Med. 2014 Feb;39(2):113-21. PMID: 23797227

17. Carlos Oliveira, Rui Costa, Amélia Estêvão, Filipe CaseiroAlves. Retroperitoneal inflammatory myofibroblastic tumor: A case report European Journal of Radiology Open Volume 4, 2017, Pages 9-12 https://doi.org/10.1016/j.ejro.2017.01.003

18. Xuewei Zeng, Huayi Huang, Jun Li, Jiayou Peng, and Jiaxiong Zhang. Emerging Technologies and Methods for Musculoskeletal Tissue Repair and Regeneration BioMed Research International / 2018 https://doi.org/10.1155/2018/5679634

\section{FIGURES}

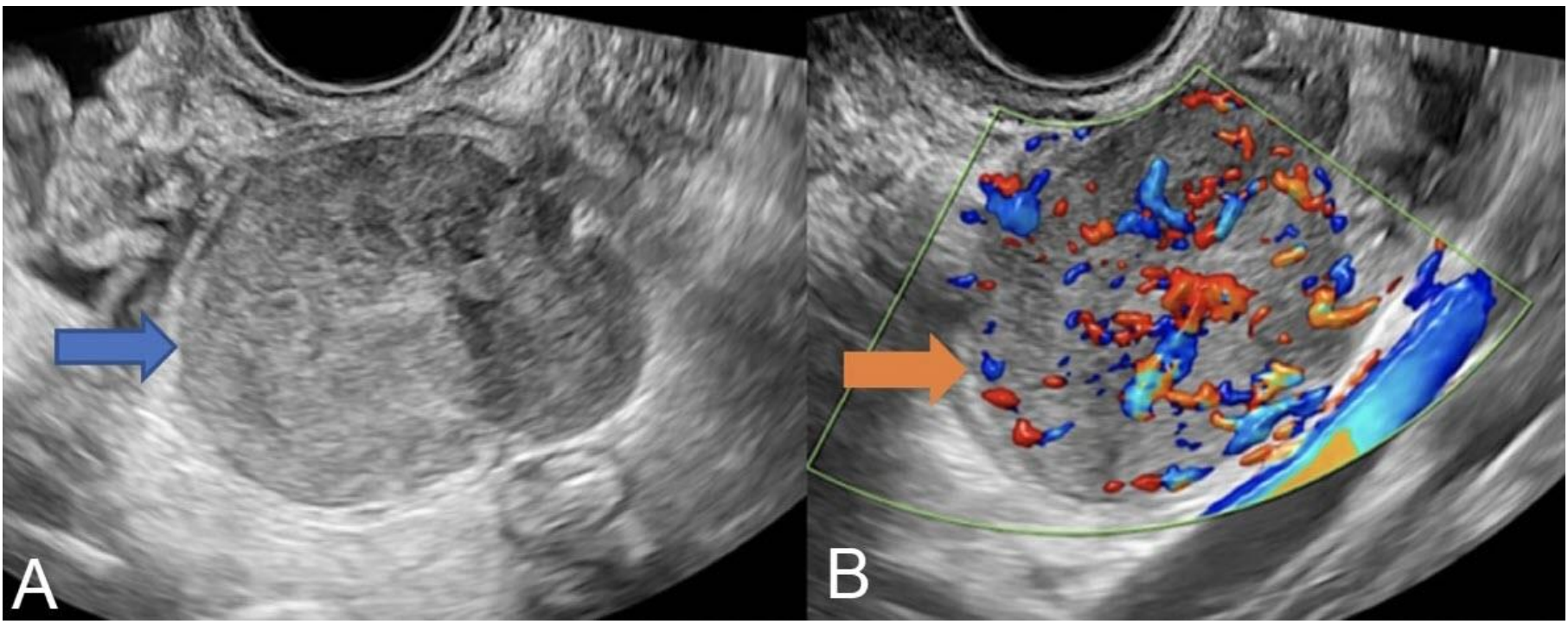

Figure 1: 23-year-old female with Inflammatory Myofibroblastic Tumor and small intestine obstruction.

FINDINGS: Well-defined solid mass (blue arrow) measuring $44 * 39 \mathrm{~mm}$ to the left of the uterus (A). The solid mass was heterogeneous (orange arrow) with avid flow on Doppler images (B).

TECHNIQUE: Real time trans-vaginal ultrasound of tumor using $20 \mathrm{mHz}$ linear probe. 


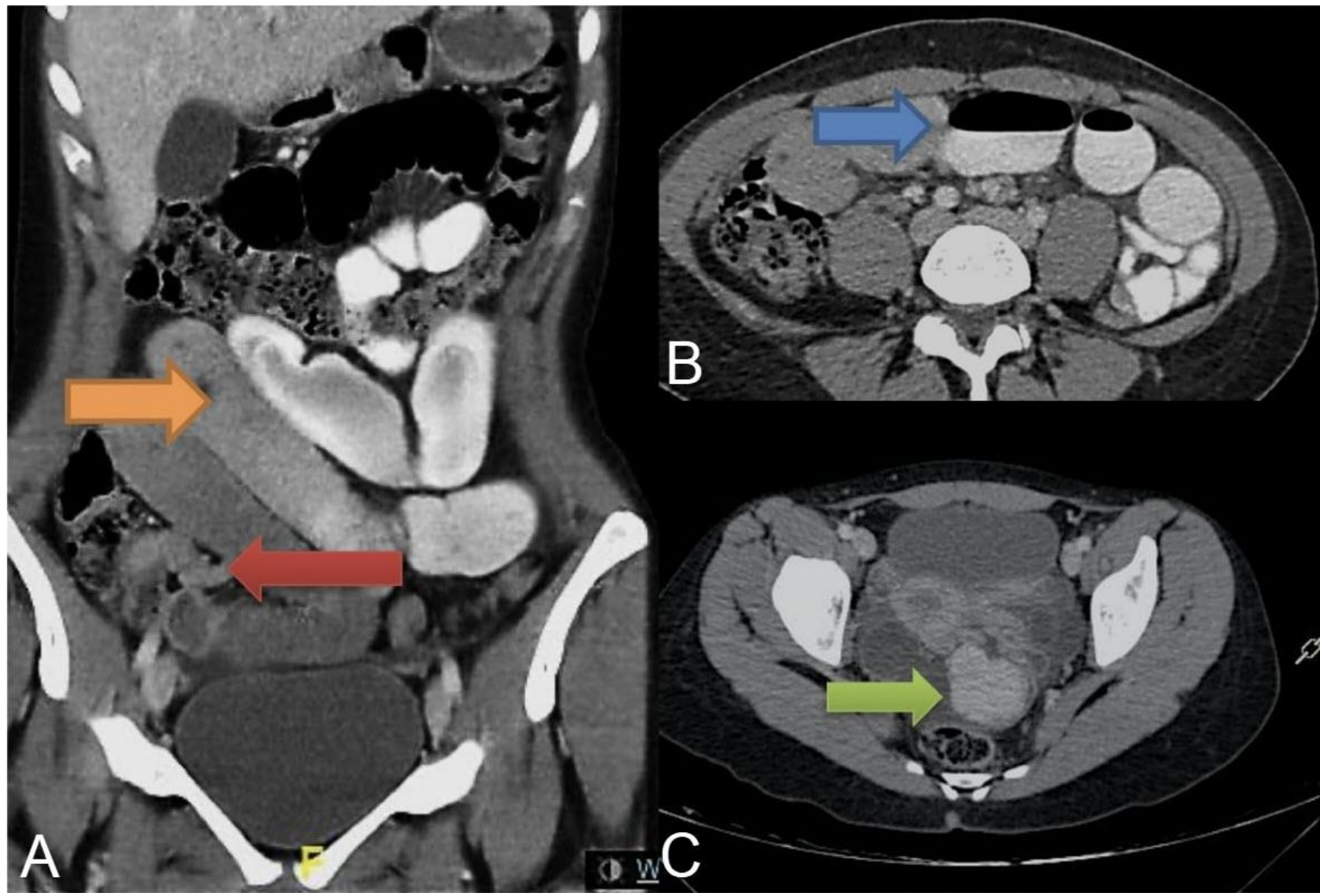

Figure 2: 23-year-old female with Inflammatory Myofibroblastic Tumor and small bowel obstruction.

FINDINGS: Complete small bowel obstruction caused by tumor that measuring $42 * 41 \mathrm{~mm}$. (A) Coronal Computer Tomography scan shows the small bowel with marked distention (orange arrow) and on (B) axial slices filled with fluid and air (blue arrow). (A)Totally collapsed bowel loops are seen after the transition zone (red arrow). (C)On axial slices well defined intraluminal encased solid mass (green arrow).

TECHNIQUE: Abdominopelvic Computer Tomography with administration of intravenous contrast material (100 ml Omnipaque 350) and oral contrast material $(1500 \mathrm{ml}$ diluted Telebrix), acquired on the portal phase with a 64 slice Computer Tomography scanner, at $3 \mathrm{~mm}$ slice thickness, $120 \mathrm{kVp}$ and $205 \mathrm{mAs}$. The images were acquired on the axial plane and coronal and sagittal reconstructions were created.

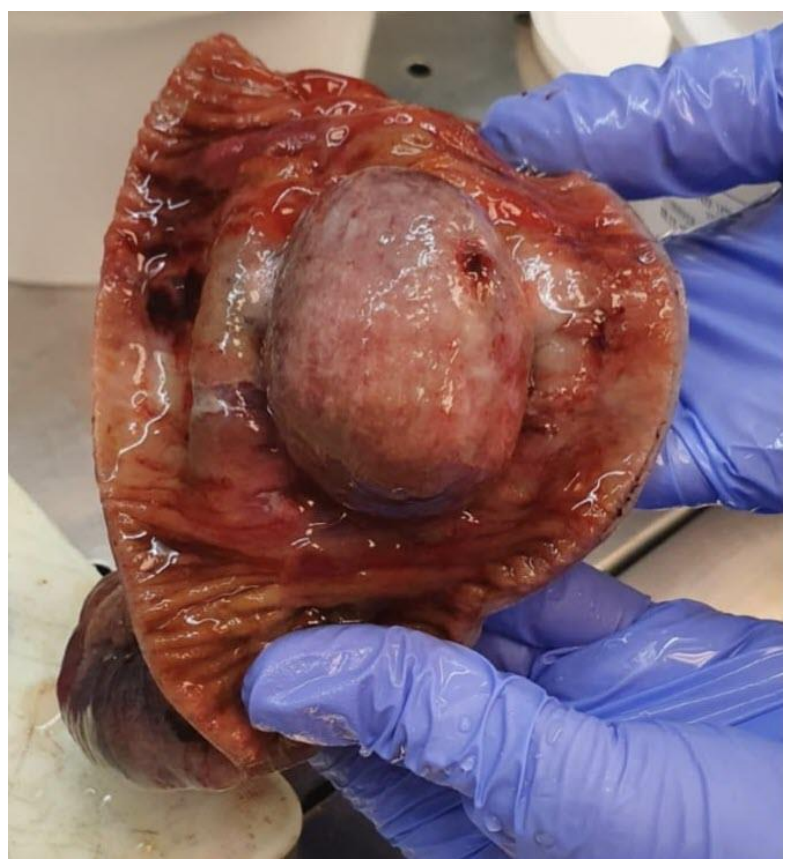

Figure 3 (left): 23-year-old female with Inflammatory Myofibroblastic Tumor and small bowel obstruction.

FINDINGS: Polypoid intestinal tumor measuring $45 * 40 \mathrm{~mm}$, covered by intact and flattened mucosa with shallow ulcerations. 

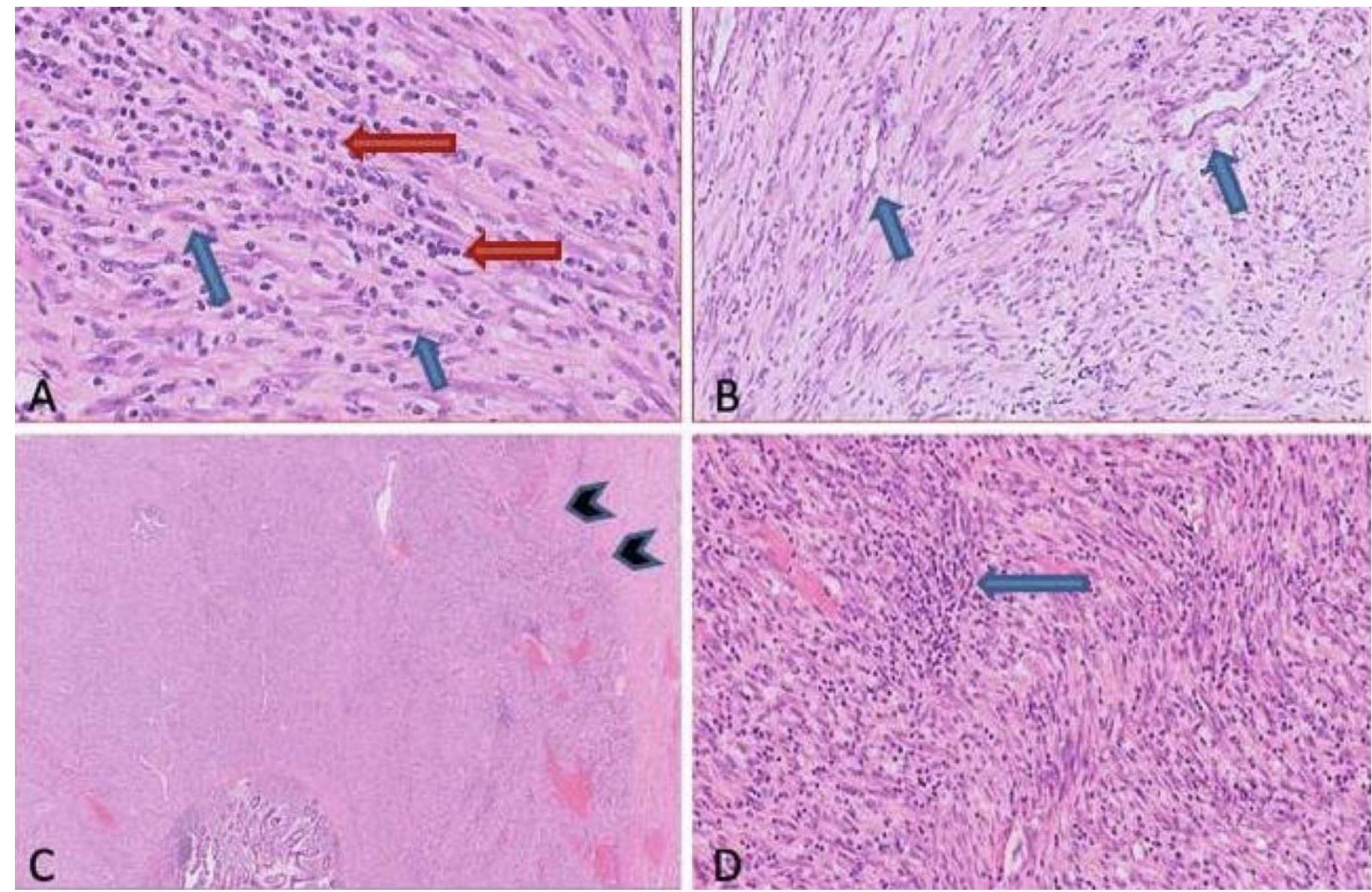

Figure 4: 23-year-old female with Inflammatory Myofibroblastic Tumor and small bowel obstruction.

FINDINGS: A: (Hematoxilin and Eosin, 40x) The tumor shows bland spindle-cells (blue arrows) with admixed lymphocytes (red arrow). B: (Hematoxilin and Eosin, 20x) The tumor may show delicate vasculature (blue arrow) and myxoid stroma. C: (Hematoxilin and Eosin, 1x) The tumor show irregular infiltration of the muscular layer (arrow heads). Note the intact mucosal layer (bottom left). D: (Hematoxilin and Eosin, 20x) The tumor shows fascicular architecture. Notice the background chronic inflammatory infiltrate (blue arrow).

TECHNIQUE: Formalin-fixed-paraffin-embedded Hematoxilin and Eosin stained sections.

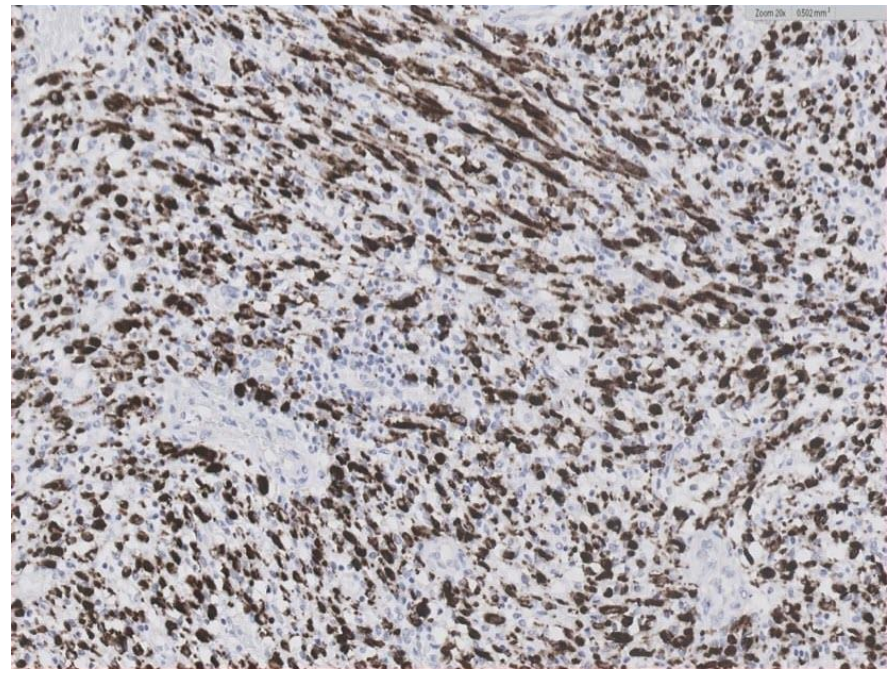

Figure 5 (left): 23-year-old female with Inflammatory Myofibroblastic Tumor and small bowel obstruction.

FINDINGS: The Inflammatory Myofibroblastic Tumor cells show positive intense cytoplasmic staining (brown).

TECHNIQUE: ROS1 (D4D6) monoclonal antibody, 1:250. 


\begin{tabular}{|l|l|}
\hline Etiology & Clearly unknown \\
\hline Incidence & $0.04-1 \%$ of all tumors of the lungs \\
\hline Gender Ratio & $1: 1$ \\
\hline Age Predilection & Children and young adults \\
\hline Risk Factors & $\begin{array}{l}\text { Infection like Campylobacter jejuni, Epstein-Barr virus, and Escherichia coli. Also, trauma, } \\
\text { steroid use, abdominal surgery, and genetic factors have been reported. }\end{array}$ \\
\hline Treatment & $\begin{array}{l}\text { Generally, surgery. Chemotherapy with or without radiotherapy has been used for patients with } \\
\text { incomplete tumor resection or positive margins. }\end{array}$ \\
\hline Prognosis & $\begin{array}{l}\text { Generally, the clinical course is benign, however intra-abdominal and retroperitoneal tumors } \\
\text { have typically shown higher local recurrence and even distant metastases. }\end{array}$ \\
\hline Findings on imaging & $\begin{array}{l}\text { Not specific, the diagnosis made by microscopic morphology only, with immunohistochemistry } \\
\text { for Anaplastic Lymphoma Kinase. }\end{array}$ \\
\hline
\end{tabular}

Table 1: Summary table of Inflammatory Myofibroblastic Tumor.

\begin{tabular}{|c|c|c|c|c|}
\hline & $\begin{array}{l}\text { Inflammatory } \\
\text { Myofibroblastic Tumor }\end{array}$ & $\begin{array}{l}\text { Gastrointestinal Stromal } \\
\text { Tumor }\end{array}$ & $\begin{array}{l}\text { Colonic } \\
\text { Leiomyomas }\end{array}$ & $\begin{array}{l}\text { Gastrointestinal } \\
\text { schwannoma }\end{array}$ \\
\hline X-ray & $\begin{array}{l}\text { Useful only in bone location } \\
\text { and can show bone } \\
\text { destruction, clear and sharp } \\
\text { boundaries, no calcification } \\
\text { or ossification, expansive } \\
\text { growth, internal ground- } \\
\text { glass opacities, an unbroken } \\
\text { sclerotic rim, and no cortical } \\
\text { involvement }\end{array}$ & $\begin{array}{l}\text { When large, secondary } \\
\text { signs of the tumour may } \\
\text { be visualised by } \\
\text { radiograph, e.g. soft tissue } \\
\text { density displacing bowel } \\
\text { loops }\end{array}$ & Generally normal & Generally normal \\
\hline Ultrasound & $\begin{array}{l}\text { Hypoechoic or hyperechoic } \\
\text { well-defined solid mass } \\
\text { with avid flow on Doppler } \\
\text { images }\end{array}$ & $\begin{array}{l}\text { A well-defined solid mass } \\
\text { lesion with central cystic } \\
\text { foci. No calcification. } \\
\text { Solid areas show } \\
\text { vascularity. }\end{array}$ & $\begin{array}{l}\text { Round or oval } \\
\text { circumscribed } \\
\text { hypoechoic solid } \\
\text { mass, often with } \\
\text { associated } \\
\text { posterior } \\
\text { shadowing due to } \\
\text { calcifications }\end{array}$ & $\begin{array}{l}\text { Oval to round mass with } \\
\text { regular or irregular marginal } \\
\text { border and lobulation of the } \\
\text { surface. Vary echogenicity } \\
\text { and homogeneity with } \\
\text { internal echogenic or cystic } \\
\text { foci and the presence of } \\
\text { exophytic development. }\end{array}$ \\
\hline CT & Soft tissue mass & $\begin{array}{l}\text { Soft tissue mass with } \\
\text { central areas of lower } \\
\text { density when necrosis is } \\
\text { present }\end{array}$ & $\begin{array}{l}\text { Soft-tissue sessile } \\
\text { mass }\end{array}$ & $\begin{array}{l}\text { Typically seen as a well- } \\
\text { defined, rounded, mural mass }\end{array}$ \\
\hline MRI & $\begin{array}{l}\text { Usually show low signal } \\
\text { intensity reflecting the } \\
\text { presence of fibrotic tissue }\end{array}$ & $\begin{array}{l}\text { Usually low signal } \\
\text { intensity on T1W and } \\
\text { high on T2W images }\end{array}$ & $\begin{array}{l}\text { Low signal } \\
\text { intensity on } \mathrm{T} 1 \mathrm{~W} \\
\text { and } \mathrm{T} 2 \mathrm{~W} \text { images }\end{array}$ & $\begin{array}{l}\text { Low or intermediate signal } \\
\text { on } \mathrm{T} 1 \mathrm{~W} \text { and high on } \mathrm{T} 2 \mathrm{~W} \\
\text { images }\end{array}$ \\
\hline $\begin{array}{l}\text { Pattern of } \\
\text { contrast } \\
\text { enhancement }\end{array}$ & $\begin{array}{l}\text { Homogeneous or } \\
\text { heterogeneous lesions, with } \\
\text { variable enhancement on } \\
\text { delayed acquisitions due to } \\
\text { the presence of fibrosis }\end{array}$ & Typically peripheral & $\begin{array}{l}\text { Homogeneous } \\
\text { attenuation }\end{array}$ & Homogeneous attenuation \\
\hline Scintigraphy & May be normal & $\begin{array}{l}\text { May be detected on Tc- } \\
99 \mathrm{~m} \text { MDP Bone } \\
\text { Scintigraphy or } 99 \mathrm{mTc}- \\
\text { RBC scintigraphy if bleed }\end{array}$ & May be normal & May be normal \\
\hline PET & Low to high FDG uptake & $\begin{array}{l}\text { Increased F-18 FDG } \\
\text { uptake }\end{array}$ & $\begin{array}{l}\text { Increased F-18 } \\
\text { FDG uptake }\end{array}$ & Increased F-18 FDG uptake \\
\hline
\end{tabular}

Table 2: Differential diagnosis table for Inflammatory Myofibroblastic Tumor. 


\section{ABBREVIATIONS}

ALK = Anaplastic Lymphoma Kinase

$\mathrm{CRP}=\mathrm{C}=$ reactive protein

$\mathrm{CT}=$ Computer Tomography

$\mathrm{ER}=$ Emergency Room

FFPE $=$ Formalin Fixed Paraffin Embedded

GIST $=$ Gastrointestinal Stromal Tumor

$\mathrm{H} \& \mathrm{E}=$ Hematoxilin and Eosin

IMTs = Inflammatory Myofibroblastic Tumors

MRI = Magnetic resonance imaging

NGS $=$ Next Generation Sequencing

US = Ultrasound

WHO $=$ World Health Organization

\section{KEYWORDS}

Inflammatory Myofibroblastic Tumor, Small bowel obstruction, Inflammatory pseudotumor, extra-pulmonary Inflammatory Myofibroblastic Tumors, Bowel solitary mast cell tumor

\section{Online access}

This publication is online available at:

www.radiologycases.com/index.php/radiologycases/article/view/3928

\section{Peer discussion}

Discuss this manuscript in our protected discussion forum at: www.radiolopolis.com/forums/JRCR

\section{Interactivity}

This publication is available as an interactive article with scroll, window/level, magnify and more features.

Available online at www.RadiologyCases.com

\section{Published by EduRad}

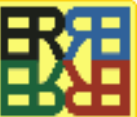

www.EduRad.org 